University of Nebraska - Lincoln

DigitalCommons@University of Nebraska - Lincoln

Public Health Resources

Public Health Resources

2016

Differences in Selected HIV Care Continuum Outcomes Among People Residing in Rural, Urban, and Metropolitan Areas - 28 US Jurisdictions

John A. Nelson

The State University of New Jersey

Anna Kinder

Casper Natrona County Health Department

Anna Satcher Johnson

Centers for Disease Control and Prevention

H. Irene Hall

Centers for Disease Control and Prevention

Xiaohong $\mathrm{Hu}$

Centers for Disease Control and Prevention

See next page for additional authors

Follow this and additional works at: http://digitalcommons.unl.edu/publichealthresources

Nelson, John A.; Kinder, Anna; Satcher Johnson, Anna; Hall, H. Irene; Hu, Xiaohong; Sweet, Donna; Guido, Alyssa; Katner, Harold; Janelle, Jennifer; Gonzalez, Maribel; Martinez Paz, Natalia; Ledonne, Charlotte; Henry, Jason; Bramel, Theresa; and Harris, Jeanne, "Differences in Selected HIV Care Continuum Outcomes Among People Residing in Rural, Urban, and Metropolitan Areas-28 US Jurisdictions" (2016). Public Health Resources. 500.

http://digitalcommons.unl.edu/publichealthresources/500

This Article is brought to you for free and open access by the Public Health Resources at DigitalCommons@University of Nebraska - Lincoln. It has been accepted for inclusion in Public Health Resources by an authorized administrator of DigitalCommons@University of Nebraska - Lincoln. 


\section{Authors}

John A. Nelson, Anna Kinder, Anna Satcher Johnson, H. Irene Hall, Xiaohong Hu, Donna Sweet, Alyssa Guido, Harold Katner, Jennifer Janelle, Maribel Gonzalez, Natalia Martinez Paz, Charlotte Ledonne, Jason Henry, Theresa Bramel, and Jeanne Harris 
ORIGINAL ARTICLE

\title{
Differences in Selected HIV Care Continuum Outcomes Among People Residing in Rural, Urban, and Metropolitan Areas-28 US Jurisdictions
}

\author{
John A. Nelson, PhD; ${ }^{1,2}$ Anna Kinder, $\mathrm{MS} ;{ }^{1,3}$ Anna Satcher Johnson, $\mathrm{MPH} ;{ }^{4} \mathrm{H}$. Irene Hall, $\mathrm{PhD} ;{ }^{4}$ \\ Xiaohong Hu, MS; ${ }^{4}$ Donna Sweet, MD; ${ }^{1,5}$ Alyssa Guido, MPH; ${ }^{6}$ Harold Katner, MD; ${ }^{1,7}$ Jennifer Janelle, MD; ;,8 \\ Maribel Gonzalez, MSN; ; ${ }^{1,9}$ Natalia Martínez Paz, MA, MPA; $;^{1,10}$ Charlotte Ledonne, BSN, MA; $;^{1,11}$ \\ Jason Henry; ${ }^{1,12}$ Theresa Bramel, MHS; ${ }^{1,13}$ \& Jeanne Harris, BSN, MBA ${ }^{1,14}$ \\ 1 Rural Health Committee, AIDS Education and Training Center Program, François-Xavier Bagnoud Center, Rutgers University School of Nursing, Newark, \\ New Jersey \\ 2 School of Nursing, Rutgers, The State University of New Jersey, Newark, New Jersey \\ 3 Casper Natrona County Health Department, Casper, Wyoming \\ 4 Centers for Disease Control and Prevention, National Center for HIVIAIDS, Viral Hepatitis, STD, and TB, Prevention; Division of HIVIAIDS Prevention, \\ Atlanta, Georgia \\ 5 School of Medicine, University of Kansas, Wichita, Kansas \\ 6 College of Medicine, University of Arizona, Tucson, Arizona \\ 7 School of Medicine, Mercer University, Macon, Georgia \\ 8 Department of Medicine, University of Florida, Gainesville, Florida \\ 9 Florida Department of Health, LaBelle, Florida \\ 10 School of Medicine, University of Washington, Seattle, Washington \\ 11 San Luis Valley Area Health Education Center, Alamosa, Colorado \\ 12 Northeast/Caribbean AIDS Education and Training Center, St. Croix, US Virgin Islands \\ 13 Alaska Native Tribal Health Consortium, Anchorage, Alaska \\ 14 College of Medicine, University of Kentucky, Lexington, Kentucky

Disclosures: The findings and conclusions in this paper are those of the authors and do not necessarily represent the views of the Centers for Disease Control and Prevention or of HRSA $\mathrm{HAB}$.

Acknowledgments: Thank you to the US Health Resources and Services Administration HIVIAIDS Bureau (HRSA HAB) AIDS Education and Training Center Program (which allows for the AETC Program Rural Health Committee) and the Division of HIVIAIDS Prevention at the Centers for Disease Control and Prevention National Center for HIVIAIDS, Viral Hepatitis, STD, and TB Prevention for their support with this study.

For further information, contact: John A. Nelson, PhD, CPNP, Rutgers, The State University of New Jersey, 65 Bergen Street, 8th Floor, Room 810B, Newark, NJ 07101; e-mail: nelsonj3@sn.rutgers.edu.

doi: $10.1111 /$ jrh. 12208

\section{Abstract}

Purpose: The HIV care continuum is used to monitor success in HIV diagnosis and treatment among persons living with HIV in the United States. Significant differences exist along the HIV care continuum between subpopulations of people living with HIV; however, differences that may exist between residents of rural and nonrural areas have not been reported.

Methods: We analyzed the Centers for Disease Control and Prevention's National HIV Surveillance System data on adults and adolescents ( $\geq 13$ years) with HIV diagnosed in 28 jurisdictions with complete reporting of HIV-related lab results. Lab data were used to assess linkage to care $(\geq 1 \mathrm{CD} 4$ or viral load test $\leq 3$ months of diagnosis), retention in care ( $\geq 2$ CD4 and/or viral load tests $\geq 3$ months apart), and viral suppression (viral load $<200$ copies $/ \mathrm{mL}$ ) among persons living with HIV. Residence at diagnosis was grouped into rural $(<50,000$ population), urban (50,000-499,999 population), and metropolitan ( $\geq 500,000$ population) categories for statistical comparison. Prevalence ratios and $95 \%$ CI were calculated to assess significant differences in linkage, retention, and viral suppression.

Findings: Although greater linkage to care was found for rural residents $(84.3 \%)$ compared to urban residents $(83.3 \%)$ and metropolitan residents $(81.9 \%)$, significantly lower levels of retention in care and viral suppression were found for residents of rural $(46.2 \%$ and $50.0 \%$, respectively) and urban $(50.2 \%$ and $47.2 \%)$ areas compared to residents of metropolitan areas $(54.5 \%$ and $50.8 \%)$.

Conclusions: Interventions are needed to increase retention in care and viral suppression among people with HIV in nonmetropolitan areas of the United States.

Key words care continuum, HIV, metropolitan, rural. 
People living in rural areas of the United States and its territories often have less access to resources and services for the management of chronic illness than people living in nonrural areas. People living with HIV (PLWH) in rural areas potentially have additional barriers including: isolating stigmas (related to one or more factors including having HIV, sexual orientation, substance use, poverty, race/ethnicity), increased risk of breaks in confidentiality, and fear of being victimized or ostracized within the rural community for disclosure of a stigmatized characteristic. ${ }^{1,2}$

The HIV care continuum has been used since $2011^{3}$ to measure progress toward best care of HIV in the United States. The continuum allows for evaluation and comparison of the percentages of persons living with diagnosed HIV, linked to HIV care, retained in care, prescribed combination antiretroviral therapy, and who have achieved viral suppression as a measure of success in diagnosis, care and treatment in particular regions of the country. Because of multiple health inequities (that may be associated with race/ethnicity, sex, sexual orientation, age, socioeconomic status, residency status), there are significant differences in some care continuum outcomes between subpopulations of PLWH in the United States. ${ }^{4-6}$

Rural residents may be at a disadvantage for accessing and receiving HIV-related services. Although the prevalence of HIV infection tends to positively correlate to population size, with a higher prevalence rate in metropolitan areas than rural areas, in the Southeast, the prevalence in rural areas can be similar to or greater than nonrural areas. ${ }^{7}$ For example, in South Carolina prevalence of HIV infection is higher among rural residents $(320 / 100,000)$ than the state collectively $(317 / 100,000) .{ }^{8}$ HIV testing among rural residents has been found to be significantly lower than among urban residents. In 1 national study, $43.6 \%$ of urban residents reported ever having been tested for HIV while only $32.2 \%$ of rural residents reported ever having been tested. ${ }^{9}$ In the most rural regions of the United States, individuals at greatest risk of acquiring HIV, based on demographics and self-reported risk factors, were found to be significantly less likely to have been tested in the last year. For residents of rural areas, only $7.3 \%$ have been HIV tested within the past year, while $13.5 \%$ of urban residents have been tested. ${ }^{9}$ Lack of HIV testing among high-risk rural residents may be contributing to disparities in late diagnoses among this population. In 2 studies comparing rural and urban residents in the Southeast, rural residents were significantly more likely to have a "late HIV diagnosis" (ie, HIV infection classified as stage 3 [AIDS] $\leq 3$ months or $<1$ year of initial HIV diagnosis). ${ }^{10,11}$

In terms of linkage to care, retention in care, and viral suppression, the picture is less clear. In a study of New
York State residents with diagnosed HIV infection, those residing outside of New York City were more likely to be linked to care within 3 months of initial diagnosis compared to those in New York City ${ }^{4}$; however, this study did not differentiate between people residing in rural and urban communities. While linkage and retention has been identified as difficult in rural communities for various reasons (primarily transportation, provider stigma and discrimination, and confidentiality concerns), ${ }^{12}$ some barriers to care have been identified as being greater for urban women compared to rural women (primarily regarding stigma and fatalism). ${ }^{13}$

A comparison of HIV care continuum outcomes for PLWH residing in metropolitan areas to those residing in rural areas has not been reported for the United States. This analysis was done to identify if there were any significant differences in linkage to care, retention in care, and viral suppression among PLWH ( $\geq 13$ years) residing in rural and nonrural jurisdictions in the United States.

\section{Methods}

We analyzed data from the Centers for Disease Control and Prevention's (CDC) National HIV Surveillance System (NHSS) on adults and adolescents ( $\geq 13$ years) with HIV diagnosed in 28 US jurisdictions with complete reporting of HIV-related laboratory test results during 2012-2014. Our aim was to determine linkage to care, retention in care, and viral suppression among residents of rural and nonrural areas. ${ }^{14}$ The 28 jurisdictions included Alabama, Alaska, Arkansas, California, the District of Columbia, Hawaii, Illinois, Indiana, Iowa, Louisiana, Maine, Maryland, Michigan, Missouri, Nebraska, New Hampshire, New York, North Dakota, Oregon, South Carolina, South Dakota, Tennessee, Texas, Utah, Virginia, Washington, West Virginia, and Wisconsin. Linkage to care was defined as $\geq 1$ CD4 or viral load (VL) test result within 3 months of diagnosis. For this study, linkage to care was assessed for people with HIV diagnosed in 2013. Retention in HIV medical care was defined as $\geq 2$ CD4 and/or VL test results at least 3 months apart during 2012 and viral suppression as the most recent VL test result of $<200$ copies per milliliter in 2012 and was assessed for persons with HIV infection diagnosed prior to 2011 who were still alive at year-end 2012. Data were reported to the CDC through December 2014.

Although the definition of "rural" is not uniform across all US government programs, ${ }^{15-17}$ "rural" is commonly defined by the US Census Bureau ${ }^{18}$ as being a territory that is populated with $<50,000$ people. For this analysis, a person's residence at HIV diagnosis was categorized as rural ( $<50,000$ population), urban (50,000-499,999 population), or metropolitan $(\geq 500,000$ 
Figure 1 Linkage to HIV Medical Care Within 3 Months After HIV Diagnosis During 2013 Among People Aged $\geq 13$ Years, by Population Category of Residence at Diagnosis-28 US Jurisdictions $(n=24,413)$.

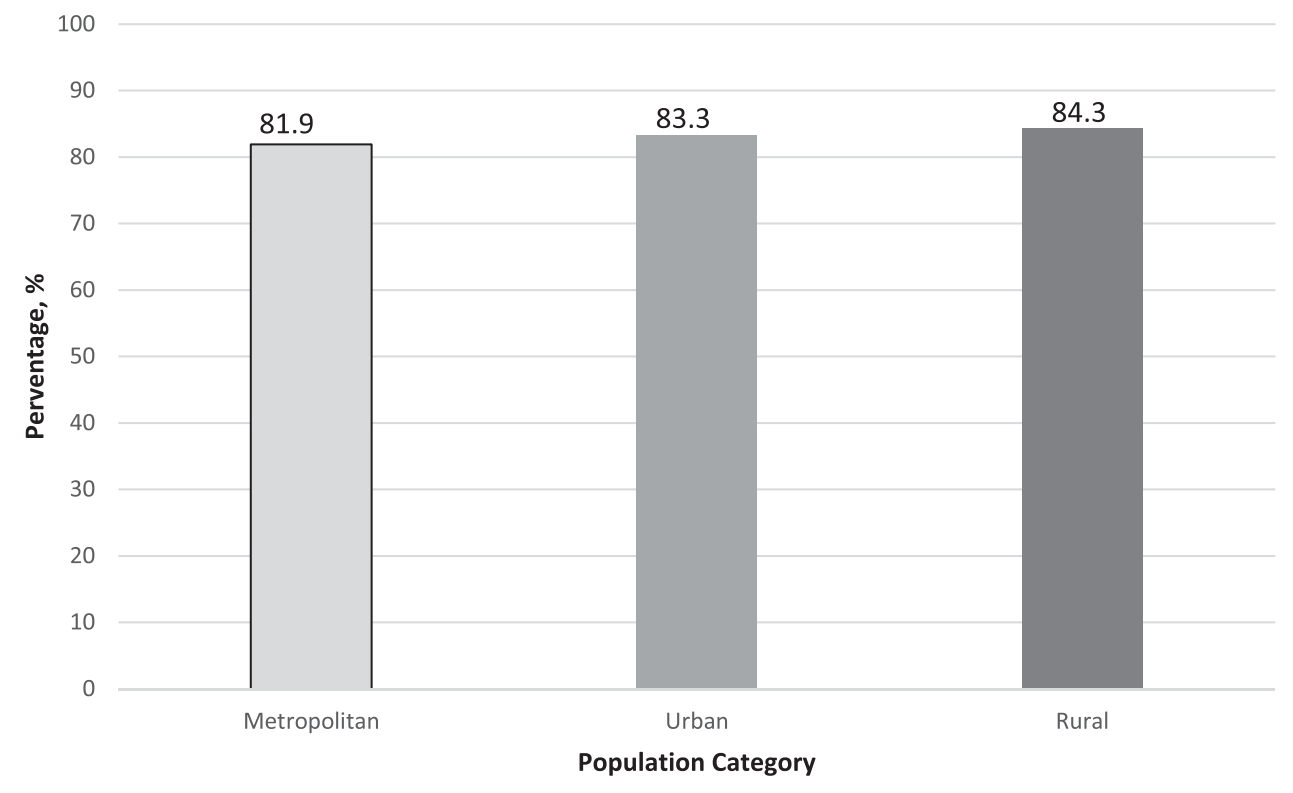

Note: Linkage to care was defined as having $\geq 1 \mathrm{CD} 4$ or VL test $\leq 3$ months after HIV diagnosis.

population). Geographic category assignments were based on the 2010 metropolitan and micropolitan statistical area delineations from the US Office of Management and Budget. ${ }^{19,20}$ While the persons included in the analyses represent a census of persons in the jurisdictions included in the analyses, the jurisdictions included could be considered a convenience sample for the United States. Therefore, prevalence ratios (PR) and 95\% CI were calculated to assess significant differences in percentages of persons linked and retained in care, and who achieved viral suppression among residents of rural and urban areas compared to residents of metropolitan areas, the referent group. The analyses did not control for potential confounding variables. PR and $95 \%$ CIs were calculated to determine differences in percentages by selected demographic characteristics (sex, age, race/ethnicity, and transmission category) for persons with HIV diagnosed in 2013 and PLWH at year-end 2012. Comparisons were made for persons with diagnosed HIV in metropolitan areas against persons with diagnosed HIV in urban or rural areas.

\section{Results}

Among 24,413 persons who received a diagnosis of HIV infection in 2013 (Table 1), 81.9\% of persons (n $=20,187$ ) residing in metropolitan areas were linked to care within 3 months after diagnosis; $83.3 \%$ (PR
$=1.02$; CI: 0.99-1.03) of persons $(\mathrm{n}=3,248)$ were linked in urban areas, and $84.3 \%(\mathrm{PR}=1.03$; CI: 0.99-1.06) of persons $(\mathrm{n}=877)$ in rural areas (Figure 1). The demographic distribution varied slightly across the geographic categories for persons with HIV diagnosed in 2013. The percentage of males ranged from $78.8 \%$ in rural areas to $81.9 \%$ metropolitan areas (Table 1). By age group, the largest group for each geographic category was persons aged 25-34 years with percentages ranging from $28.4 \%$ in urban areas to $31.8 \%$ in metropolitan areas. By race/ethnicity, the largest group for each geographic category was blacks/African Americans with percentages ranging from $41.4 \%$ in both urban and rural areas to $43.9 \%$ in metropolitan areas. Males with infection attributed to male-tomale sexual contact accounted for the largest percentage of persons with diagnosed HIV by transmission category, with percentages ranging from $57.2 \%$ in rural areas to $69.1 \%$ in metropolitan areas. Using PR, persons in rural areas compared to persons in metropolitan areas were found more likely to be female $(\mathrm{PR}=1.17$; CI: 1.03 1.34) and white (PR = 1.45; CI: 1.32-1.59), and less likely to have acquired HIV as a result of male-to-male sexual contact only (PR =0.83; CI: 0.78-0.88).

Among 530,250 PLWH diagnosed through year-end 2011 (Table 2), 54.5\% of persons $(n=447,749)$ residing in metropolitan areas at the time of HIV diagnosis were retained in HIV medical care during 2012, 50.2\% 
Table 1 Diagnoses of HIV Infection Among Adults and Adolescents, by Geographic Population Category and Selected Characteristics, 27 States and the District of Columbia

\begin{tabular}{|c|c|c|c|c|c|c|c|c|c|c|}
\hline \multirow[b]{2}{*}{ Sex } & \multicolumn{2}{|c|}{$\begin{array}{c}\text { Metropolitan } \\
(\text { Pop } \geq 500,000)\end{array}$} & \multicolumn{2}{|c|}{$\begin{array}{c}\text { Urban (Pop } \\
50,000-499,999)\end{array}$} & \multicolumn{2}{|c|}{$\begin{array}{l}\text { Rural (Pop } \\
<50,000 \text { ) }\end{array}$} & \multicolumn{2}{|c|}{ Unknown } & \multicolumn{2}{|c|}{ Total } \\
\hline & No. & $\%$ & No. & $\%$ & No. & $\%$ & No. & $\%$ & No. & $\%$ \\
\hline Male & 16,535 & 81.9 & 2,607 & 80.3 & 691 & 78.8 & 86 & 85.1 & 19,919 & 81.6 \\
\hline Female & 3,652 & 18.1 & 641 & 19.7 & 186 & 21.2 & 15 & 14.9 & 4,494 & 18.4 \\
\hline \multicolumn{11}{|l|}{ Age at diagnosis } \\
\hline $13-24$ & 4,466 & 22.1 & 772 & 23.8 & 168 & 19.2 & 13 & 12.9 & 5,419 & 22.2 \\
\hline $25-34$ & 6,420 & 31.8 & 905 & 27.9 & 249 & 28.4 & 27 & 26.7 & 7,601 & 31.1 \\
\hline $35-44$ & 4,096 & 20.3 & 660 & 20.3 & 196 & 22.3 & 17 & 16.8 & 4,969 & 20.4 \\
\hline $45-54$ & 3,378 & 16.7 & 562 & 17.3 & 169 & 19.3 & 24 & 23.8 & 4,133 & 16.9 \\
\hline$\geq 55$ & 1,827 & 9.1 & 349 & 10.7 & 95 & 10.8 & 20 & 19.8 & 2,291 & 9.4 \\
\hline \multicolumn{11}{|l|}{ Race/ethnicity } \\
\hline $\begin{array}{c}\text { American Indian/ } \\
\text { Alaska Native }\end{array}$ & 30 & 0.1 & 15 & 0.5 & 13 & 1.5 & 0 & 0 & 58 & 0.2 \\
\hline Asian & 585 & 2.9 & 54 & 1.7 & 4 & 0.5 & 3 & 3 & 646 & 2.6 \\
\hline $\begin{array}{c}\text { Black/African } \\
\text { American }\end{array}$ & 8,853 & 43.9 & 1,344 & 41.4 & 363 & 41.4 & 45 & 44.6 & 10,605 & 43.4 \\
\hline Hispanic/Latino ${ }^{a}$ & 5,091 & 25.2 & 504 & 15.5 & 163 & 18.6 & 21 & 20.8 & 5,779 & 23.7 \\
\hline $\begin{array}{l}\text { Native Hawaiian/ } \\
\text { Other Pacific } \\
\text { Islander }\end{array}$ & 36 & 0.2 & 11 & 0.3 & 0 & 0 & 0 & 0 & 47 & 0.2 \\
\hline White & 4,952 & 24.5 & 1,227 & 37.8 & 311 & 35.5 & 28 & 27.7 & 6,518 & 26.7 \\
\hline Multiple races & 640 & 3.2 & 93 & 2.9 & 23 & 2.6 & 4 & 4 & 760 & 3.1 \\
\hline \multicolumn{11}{|c|}{ Transmission category ${ }^{b}$} \\
\hline $\begin{array}{l}\text { Male-to-male } \\
\text { sexual contact }\end{array}$ & 13,951 & 69.1 & 2,084 & 64.2 & 502 & 57.2 & 53 & 52.4 & 16,590 & 68 \\
\hline Injection drug use & 1,076 & 5.3 & 240 & 7.4 & 77 & 8.8 & 16 & 16.1 & 1,409 & 5.8 \\
\hline $\begin{array}{l}\text { Male-to-male } \\
\text { sexual contact } \\
\text { and injection } \\
\text { drug use }\end{array}$ & 584 & 2.9 & 114 & 3.5 & 36 & 4.1 & 4 & 4 & 739 & 3 \\
\hline $\begin{array}{c}\text { Heterosexual } \\
\text { contact }^{c}\end{array}$ & 4,511 & 22.3 & 801 & 24.7 & 261 & 29.7 & 28 & 27.5 & 5,600 & 22.9 \\
\hline Other ${ }^{d}$ & 65 & 0.3 & 9 & 0.3 & 1 & 0.1 & 0 & 0 & 75 & 0.3 \\
\hline Total & 20,187 & 100 & 3,248 & 100 & 877 & 100 & 101 & 100 & 24,413 & 100 \\
\hline
\end{tabular}

Data include persons with diagnosed HIV infection regardless of stage of disease at diagnosis.

a Hispanics/Latinos can be of any race.

${ }^{b}$ Data have been statistically adjusted to account for missing transmission category.

${ }^{c}$ Heterosexual contact with a person known to have, or to be at high risk for, HIV infection.

${ }^{d}$ Includes persons whose infection was attributed to hemophilia, blood transfusion, or perinatal exposure or whose risk factor was not reported or not identified.

of persons $(\mathrm{n}=62,486)$ in urban areas $(\mathrm{PR}=0.92$; CI: $0.91-0.93)$ and $50.0 \%$ of persons $(n=15,581)$ in rural areas ( $\mathrm{PR}=0.92 ; \mathrm{CI}=0.90,0.93$; Figure 2). Among the same population used to measure retention, viral suppression was achieved in 2012 by $50.8 \%$ among those residing in metropolitan areas at the time of HIV diagnosis, $47.2 \%$ ( $\mathrm{PR}=0.93$; CI: $0.92-0.94)$ in urban areas, and $46.2 \%(P R=0.91$; CI: $0.90-0.93)$ of those in rural areas (Figure 2). There was some variation in the demographic distribution across the geographic categories for persons living with diagnosed HIV at year-end 2012.
The percentage of males ranged from $72.1 \%$ in rural areas to $77.5 \%$ in urban areas (Table 2 ). By age group, the largest group for each geographic category was persons aged 45-54 years with percentages ranging from $35.1 \%$ in rural areas to $35.5 \%$ in urban areas. By race/ethnicity, blacks/African Americans accounted for the largest group in metropolitan $(40.6 \%)$ and rural $(45.2 \%)$ areas. Whites accounted for the largest racial/ethnic group (42.7\%) in urban areas. Males with infection attributed to male-to-male sexual contact accounted for the largest percentage of persons with diagnosed HIV by transmis- 
Table 2 Persons With HIV Infection Diagnosed by Year-End 2011 and Alive at Year-End of 2012, by Geographic Population Category and Selected Characteristics, 2012, 27 States and the District of Columbia

\begin{tabular}{|c|c|c|c|c|c|c|c|c|c|c|}
\hline \multirow[b]{2}{*}{ Sex } & \multicolumn{2}{|c|}{$\begin{array}{c}\text { Metropolitan } \\
(\mathrm{Pop} \geq 500,000)\end{array}$} & \multicolumn{2}{|c|}{$\begin{array}{c}\text { Urban (Pop } \\
50,000-499,999)\end{array}$} & \multicolumn{2}{|c|}{$\begin{array}{r}\text { Rural (Pop } \\
<50,000)\end{array}$} & \multicolumn{2}{|c|}{ Unknown } & \multicolumn{2}{|c|}{ Total } \\
\hline & No. & $\%$ & No. & $\%$ & No. & $\%$ & No. & $\%$ & No. & $\%$ \\
\hline Male & 344,222 & 76.9 & 48,419 & 77.5 & 11,235 & 72.1 & 3,607 & 81.3 & 407,483 & 76.8 \\
\hline Female & 103,527 & 23.1 & 14,067 & 22.5 & 4,346 & 27.9 & 827 & 18.7 & 122,767 & 23.2 \\
\hline \multicolumn{11}{|l|}{ Age at end of 2011} \\
\hline $13-24$ & 19,490 & 4.4 & 2,846 & 4.6 & 695 & 4.5 & 145 & 3.3 & 23,176 & 4.4 \\
\hline $25-34$ & 62,556 & 14 & 9,235 & 14.8 & 2,235 & 14.3 & 354 & 8 & 74,380 & 14 \\
\hline $35-44$ & 110,052 & 24.6 & 15,965 & 25.5 & 4,109 & 26.4 & 953 & 21.5 & 131,079 & 24.7 \\
\hline $45-54$ & 158,328 & 35.4 & 22,156 & 35.5 & 5,475 & 35.1 & 1,916 & 43.2 & 187,875 & 35.4 \\
\hline$\geq 55$ & 97,323 & 21.7 & 12,284 & 19.7 & 3,067 & 19.7 & 1,066 & 24 & 113,740 & 21.5 \\
\hline \multicolumn{11}{|l|}{ Race/ethnicity } \\
\hline $\begin{array}{c}\text { American Indian/ } \\
\text { Alaska Native }\end{array}$ & 742 & 0.2 & 278 & 0.4 & 140 & 0.9 & 15 & 0.3 & 1,175 & 0.2 \\
\hline Asian & 7,207 & 1.6 & 535 & 0.9 & 40 & 0.3 & 45 & 1 & 7,827 & 1.5 \\
\hline $\begin{array}{l}\text { Black/African } \\
\text { American }\end{array}$ & 182,773 & 40.8 & 23,682 & 37.9 & 7,036 & 45.2 & 1,666 & 37.6 & 215,157 & 40.6 \\
\hline Hispanic/Latino ${ }^{a}$ & 104,327 & 23.3 & 8,967 & 14.4 & 1,885 & 12.1 & 807 & 18.2 & 115,986 & 21.9 \\
\hline $\begin{array}{l}\text { Native Hawaiian/ } \\
\text { Other Pacific } \\
\text { Islander }\end{array}$ & 505 & 0.1 & 116 & 0.2 & 1 & 0 & 4 & 0.1 & 626 & 0.1 \\
\hline White & 136,066 & 30.4 & 26,700 & 42.7 & 5,955 & 38.2 & 1,724 & 38.9 & 170,445 & 32.1 \\
\hline Multiple races & 16,129 & 3.6 & 2,208 & 3.5 & 524 & 3.4 & 173 & 3.9 & 19,034 & 3.6 \\
\hline \multicolumn{11}{|l|}{$\begin{array}{c}\text { Transmission } \\
\text { category }^{b}\end{array}$} \\
\hline $\begin{array}{l}\text { Male-to-male sexual } \\
\text { contact }\end{array}$ & 246,737 & 55.1 & 30,337 & 48.5 & 6,420 & 41.2 & 2,355 & 53.1 & 285,848 & 53.9 \\
\hline Injection drug use & 66,159 & 14.8 & 10,955 & 17.5 & 3,020 & 19.4 & 823 & 18.6 & 80,957 & 15.3 \\
\hline $\begin{array}{l}\text { Male-to-male sexual } \\
\text { contact and } \\
\text { injection drug use }\end{array}$ & 25,744 & 5.7 & 5,120 & 8.2 & 1,135 & 7.3 & 351 & 7.9 & 32,349 & 6.1 \\
\hline $\begin{array}{l}\text { Heterosexual } \\
\text { contact }^{c}\end{array}$ & 102,118 & 22.8 & 15,130 & 24.2 & 4,718 & 30.3 & 790 & 17.8 & 122,755 & 23.2 \\
\hline Other ${ }^{d}$ & 6,992 & 1.6 & 945 & 1.5 & 288 & 1.9 & 115 & 2.6 & 8,340 & 1.6 \\
\hline Total & 447,749 & 100 & 62,486 & 100 & 15,581 & 100 & 4,434 & 100 & 530,250 & 100 \\
\hline
\end{tabular}

Data include persons with diagnosed HIV infection regardless of stage of disease at diagnosis.

aHispanics/Latinos can be of any race.

${ }^{b}$ Data have been statistically adjusted to account for missing transmission category.

cHeterosexual contact with a person known to have, or to be at high risk for, HIV infection.

${ }^{d}$ Includes persons whose infection was attributed to hemophilia, blood transfusion, or perinatal exposure or whose risk factor was not reported or not identified.

sion category, with percentages ranging from $41.2 \%$ in rural areas to $55.1 \%$ in metropolitan areas. Persons living with diagnosed HIV in rural areas at the end of 2012 were more likely than persons in metropolitan areas to be female ( $\mathrm{PR}=1.21$; CI: 1.18-1.24), white ( $\mathrm{PR}=1.26$; CI: 1.23-1.28) or black/African American (PR = 1.11; CI: 1.09-1.13), and less likely to be Hispanic/Latino (PR
$=0.52$; CI: $0.50-0.54)$ or to have acquired HIV infection through male-to-male sexual contact $(\mathrm{PR}=0.75$; CI: 0.73-0.76). Age distributions were similar across the geographic categories; however, rural persons were more likely to be 35-44 years old ( $\mathrm{PR}=1.07$; CI: 1.04-1.10), and slightly less likely to be 55 years or older $(\mathrm{PR}=0.91$; CI: 0.88-0.94). 
Figure 2 Retention in HIV Medical Care and Viral Suppression, Among People Aged $\geq 13$ Years With HIV Infection Diagnosed by Year-End 2011 and Alive at Year-End 2012, by Population Category of Residence at Diagnosis-28 US Jurisdictions ( $n=530,250)$.

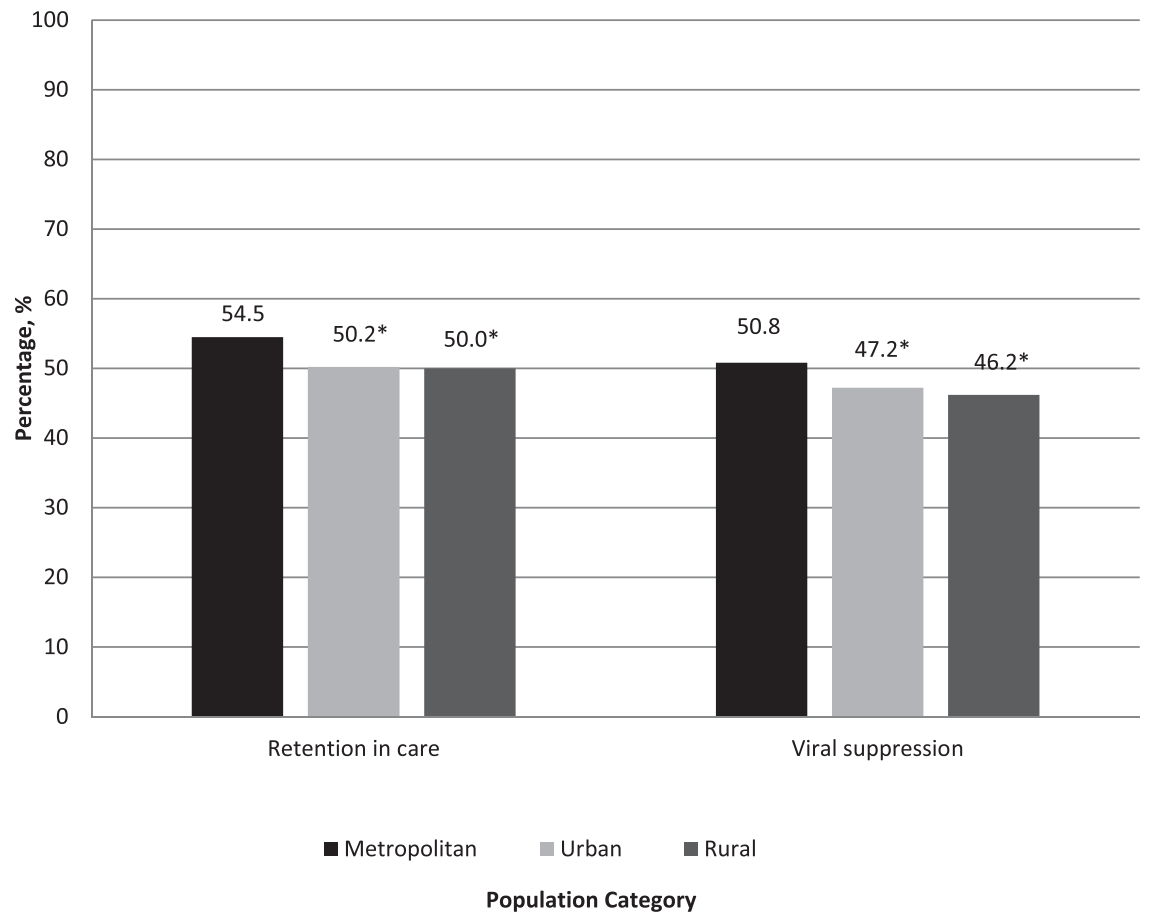

Note: Retention in care was defined as 2 or more CD4 or VL tests performed at least 3 months apart during 2012. Viral suppression was defined as a VL result of $<200$ copies/mL.

*Statistically significant compared with metropolitan.

\section{Discussion}

In all population categories, the majority of people who received a diagnosis of HIV in 2013 were promptly linked to care. The percentage retained in care and virally suppressed was significantly lower among PLWH who were initially diagnosed in rural areas. Percentage distributions were similar for linkage to care, retention in care, and viral suppression between persons in urban and rural areas.

Some differences in percentages of persons with HIV diagnosed in 2013 and PLWH by year-end 2012 (and initially diagnosed by year-end of 2011) by demographic group were found when comparing persons in rural and metropolitan areas and may have contributed to the findings of this study. Another limitation of this study is whether or not there were significant differences in HIV morbidity at the time of diagnosis between the rural, urban, and metropolitan populations. Some studies ${ }^{10,11}$ have indicated that living in a rural area is associated with being older, having a more advanced stage classification at initial diagnosis, and being diagnosed with AIDS sooner following HIV diagnosis. PLWH in rural areas may link to care more readily as a result of symptoms or being older, but then subsequently drop out of care after linkage. Availability of services (pharmacy access, antiretroviral medications, and mental health services) for PLWH vary from 1 rural community to another and geographical barriers for PLWH in these areas may result from several factors including time/distance to nearest medical facility, availability of providers, environmental barriers to accessing care (ie, poor roads), lack of communication services, stigma, and availability of HIV care support. ${ }^{12,21,22}$

Retention in care and viral suppression was assessed for the prevalent (all persons living with diagnosed HIV) populations of each geographic category to highlight the gaps that may exist in connecting persons to sustained, quality care. Theoretically, 100\% of persons with diagnosed HIV should be linked to care, retained in care, and virally suppressed. However, the US HIV care continuum has resembled more of a cascade since first described in $2011 .^{3}$ To guide local, state, and national efforts to increase the percentages of people engaged in the continuum from HIV diagnosis to viral suppression, the National HIV/AIDS Strategy ${ }^{23}$ emphasizes prevention and intervention service provision at clinics, community 
centers, and nontraditional settings (eg, mental health centers). These services include HIV testing, as well as linkage to and retention in long-term quality care that seeks to sustain viral suppression through promotion of adherence after timely initiation of antiretroviral therapy and provision of coordinated care for therapy-associated complications, other coinfections, substance addiction, and mental health issues. ${ }^{24,25}$ HIV prevention and intervention service delivery should be expanded to vulnerable populations in rural health settings; however, local jurisdictions should consider the impact of migration after initial diagnosis among people diagnosed in nonmetropolitan areas in program planning. Previous studies $^{26-28}$ have found persons from rural areas may migrate to more populated municipalities after HIV diagnosis for fear of stigma, confidentiality issues, and availability of appropriate HIV-related medical care. Future studies should follow and assess retention in care in larger geographic areas among persons who are initially linked to care in rural areas.

This analysis was subject to several additional limitations. Data were available from 28 US jurisdictions with complete reporting of HIV-related lab data to the CDC; these jurisdictions may not be representative of all people with diagnosed HIV infection in the United States during the study time period, and these jurisdictions were not evaluated for differences in resource availability (ie, equal availability of HIV testing and HIV care services). The residence used to designate cases into the 3 population categories for PLWH was based on their residence at the time of initial HIV diagnosis. Retention in care and viral suppression among people who have moved from a rural region to a nonrural region, or from a metropolitan area to a nonmetropolitan area, may not be the same as that associated with the residence at diagnosis. Since CD4 and VL test results reported to HIV surveillance programs were relied on to monitor linkage and retention in care and viral suppression, not having these tests done or reported limits the inclusion criteria for linkage and retention in care. Some people with HIV may have care visits that do not result in a CD4 or VL lab test. Data on CD4 and VL test results during the follow-up period may be missing for people who moved to a jurisdiction after HIV diagnosis that did not report VL test results to the NHSS.

Lower levels of retention in care and viral suppression were observed among PLWH who resided in rural areas at the time of diagnosis. The targeted goals of the US National HIV/AIDS Strategy ${ }^{23}$ by 2020 include: $85 \%$ of all newly diagnosed HIV-infected persons will be linked to care within 1 month of diagnosis, $90 \%$ of all identified PLWH will be retained in care, and $80 \%$ of all PLWH will be virally suppressed. Establishment of solid prevention, intervention, care, and treatment infrastruc- tures are needed to enhance care and treatment for PLWH in all geographic areas of the United States, including people residing in rural areas.

\section{References}

1. Huff A, Chumblerb N, O’Brien Cherry C, Hilld M, Veguillab V. An in-depth mixed-methods approach to Ryan White HIV/AIDS care program comprehensive needs assessment from the Northeast Georgia Public Health District: the significance of patient privacy, psychological health, and social stigma to care. Eval Program Plann. 2015;49:137-148.

2. Cordova W, Cooper HS, Avant F. Factors that impact service delivery to individuals living with HIV/AIDS in rural northeastern Texas. Contemporary Rural Social Work. 2011;3:59-77.

3. Gardner EM, McLees MP, Steiner JF, del Rio C, Burman WJ. The spectrum of engagement in HIV care and its relevance to test-and-treat strategies for prevention of HIV infection. Clin Infect Dis. 201 1;52(6):793-800.

4. Gordon D, Bian F, Anderson BJ, Smith LC. Timing of entry to care by newly diagnosed HIV cases before and after the 2010 New York State HIV testing law. J Acq Immun Def Synd. 2015;68(Suppl 1):S54-S58.

5. Maulsby C, Charles V, Kinsky S, Riordan M, Jain K, Holtgrave D. Positive charge: filling the gaps in the U.S. HIV continuum of care. AIDS Behav. 2015;19(11):2097-2107.

6. Rosenberg ES, Millett GA, Sullivan PS, del Rio C, Curran JW. Understanding the HIV disparities between black and white men who have sex with men in the USA using the HIV care continuum: A modelling study. Lancet HIV. 2014;1(3):e112-e118.

7. Vyavaharkar M, Glover S, Leonhirth D, Probst J. HIV/AIDS in rural America: prevalence and service availability. South Carolina Rural Health Research Center. January 2013. Available at: http://rhr.sph. sc.edu/report/(11-1)HIV\%20AIDS\%20in\%20Rural\% 20America.pdf. Accessed January 1, 2016.

8. Centers for Disease Control and Prevention. HIV Surveillance Report, 2014; vol. 26. Available at: http://www.cdc.gov/hiv/library/reports/surveillance/. Published November 2015. Accessed January 1, 2016.

9. Ohl ME, Perencevich E. Frequency of human immunodeficiency virus (HIV) testing in urban vs. rural areas of the United States: results from a nationally-representative sample. BMC Public Health. 2011;11:681. doi:10.1186/1471-2458-11-681

10. Trepka MJ, Fennie KP, Sheehan DM, Lutfi K, Maddox L, Lieb S. Late HIV diagnosis: differences by rural/urban residence, Florida, 2007-2011. AIDS Patient Care ST. 2014;28(4):188-197.

11. Weis KE, Liese AD, Hussey J, Gibson JJ, Duffus WA. Associations of rural residence with timing of HIV 
diagnosis and stage of disease at diagnosis, South Carolina 2001-2005. J Rural Health. 2010;26(2):105-112.

12. Pellowski JA. Barrier to care for rural people living with HIV: a review of domestic research and health care models. J Assoc Nurses Aids Care. 2013;24(5):422-437.

13. Eastwood EA, Fletcher J, Quinlivan EB, Verdecias N, Birnbaum JM, Blank AE. Baseline social characteristics and barriers to care from a special projects of national significance women of color with HIV study: a comparison of urban and rural women and barriers to HIV care. AIDS Patient Care ST. 2015;29:S4-S10.

14. Centers for Disease Control and Prevention. Monitoring selected national HIV prevention and care objectives by using HIV surveillance data-United States and 6 dependent areas-2013. HIV Surveillance Supplemental Report 2015. 20(No. 2). Available at: http://www.cdc.gov/hiv/library/reports/surveillance/. Published July 2015. Accessed January 4, 2016.

15. Hart LG, Larson EH, Lishner DM. Rural definitions for health policy and research. Am J Public Health. 2005;95(7):1149-1155.

16. Coburn AF, MacKinney AC, McBride TD, Mueller KJ, Slifkin RT, Wakefield MK. Choosing Rural Definitions: Implications for Health Policy. Rural Policy Research Institute Health Panel. March 2007. Available at: http://www.rupri.org/Forms/RuralDefinitionsBrief.pdf. Accessed January 1, 2016.

17. HRSA. Defining the Rural Population. Available at: http://www.hrsa.gov/ruralhealth/aboutus/definition. html. Accessed January 4, 2016.

18. United States Census Bureau. Geographic Terms and Concepts - Urban and Rural. Available at: http://www. census.gov/geo/reference/gtc/gtc_urbanrural.html. Accessed January 4, 2016.

19. Office of Management and Budget. Standards for delineating metropolitan and micropolitan statistical areas. Federal Register. 2010;75(123):37246-39052. Available at: http://go.usa.gov/vSpG. Published June 28, 2010. Accessed January 4, 2016.

20. Revised definitions of metropolitan statistical areas, new definitions of micropolitan statistical areas and combined statistical areas, and guidance on uses of the delineations of these areas. OMB Bulletin 13-01. Office of Management and Budget. Available at:
http://go.usa.gov/vSyB. Published February 28, 2013. Accessed January 4, 2016.

21. Committee on Review Data Systems for Monitoring HIV Care; Institute of Medicine; Ford MA, Spicer CM, editors. Monitoring HIV Care in the United States: Indicators and Data Systems. Washington, DC: National Academies Press; 2012 Mar 15. 2, Indicators Related to Continuous HIV Care and Access to Supportive Services. Available at: http://www.ncbi.nlm.nih.gov/books/NBK201376/. Accessed July 4, 2016.

22. Reif S, Golin CE, Smith SR. Barriers to accessing HIV/AIDS care in North Carolina: Rural and urban differences. AIDS Care. 2005;17(5):558-565.

23. National HIV/AIDS Strategy for the United States: Updated to 2020. Available at: https://www.aids.gov/federal-resources/national-hivaids-strategy/nhas-update.pdf. Published July 2015. Accessed January 4, 2016.

24. Centers for Disease Control and Prevention. Program collaboration and service integration: enhancing the prevention and control of HIV/AIDS, viral hepatitis, sexually transmitted diseases, and tuberculosis in the United States. Available at: http://www.

cdc.gov/nchhstp/programintegration/docs/207181C_NCHHSTP_PCSI\%20WhitePaper-508c.pdf. Accessed January 4, 2016.

25. Substance Abuse and Mental Health Services Administration. Minority AIDS initiative continuum of care pilot - integration of HIV prevention and medical care into mental health and substance abuse treatment programs for racial/ethnic minority populations at high risk for behavioral health disorders and HIV. April 24, 2014. Available at: http://www.samhsa.gov/grants/grantannouncements/ti-14-013. Accessed January 4, 2016.

26. Agee BS, Funkhouser E, Roseman JM, Fawal H, Holmberg SD, Vermund S. Migration patterns following HIV diagnosis among adults residing in the nonurban Deep South. AIDS Care. 2006;18(S1):51-58.

27. Ellerbrock TV, Chamblee S, Bush TJ. Human immunodeficiency virus infection in a rural community in the United States. Am J Epidemiol. 2004;160:582-588.

28. Berk ML, Schur CL, Dunbar JL, Bozzette S, Shapiro M. Short report: migration among persons living with HIV. Soc Sci Med. 2003;57:1091-1097. 